\title{
Role of Nano-Biotechnology in Agriculltural Sector
}

Advance Research in

\section{Organic and Inorganic}

\section{Chemistry (AROIC)}

\section{Volume 2 Issue 1, 2021}

Article Information

Received date : December 15, 2021

Published date: December 30, 2021

\section{${ }^{*}$ Corresponding author}

Waleed Fouad Abobatta, Horticulture

Research Institute, Agriculture Research Centre, Egypt

\section{Keywords}

Nano-Biotechnology; Agricultural Sector Nano Fertilizers; Nano Sensor

\section{DOI: 10.54026/AROIC/1004}

Distributed under Creative Commons CC-BY 4.0
Waleed Fouad Abobatta*

Horticulture Research Institute, Agriculture Research Centre, Egypt

\section{Abstract}

Nano-biotechnology applications use in various fields in the last decades, while, Nano-biotechnology has a significan role in the agricultural sector. There are various challenges facing agriculture production, particularly climate change conditions and biotic stress such as pathogens and insects, which affects negatively various crop production, particularly the horticultural crops. Nanotechnology is considered a key tool for improving agricultural production, there are numerous advantages of the application of Nano-biotechnology like target delivery of various agrochemicals for specific sites in plant tissue, enhancing plant tolerance, increase nutrient efficiency, which improves plant growth. Nanoparticles are manufactured by different techniques, while, there are two main methods to manufacture (top to down), and bottom-up. There are different unique properties of nanomaterials such as higher charge density and higher reactivity due to (High surface to volume ratio), higher penetration of plant tissues, strength, and heat resistance. There are different applications of nanotechnology in the agricultural field that include nano fertilizers, nanocides, biosensors, nano-carriers, nano herbicides, Analysis of gene expression, and application in post-harvest processing such as nano-coating materials and nano packaging. In addition application of nanotechnology in precision agriculture. Bio-Nano application in the agricultural fields sustained the environment, protecting both soil and water from pollution by agrochemicals, and increasing crop productivity.

\section{Introduction}

There is more attention to the use of Nano-biotechnology applications in various fields from the last few decades, whereas, in the agricultural sector, Nano-biotechnology has precious characters in the delivery of various agrochemicals for enhancing plant tolerance, plant growth, and nutrient use [1]. Nano technologies are the potential technology that studies the materials at nanometer dimensions $(1-100 \mathrm{~nm})$, it is a novel scientific branch is considered as a key solution to numerous problems in agriculture production, by providing the opportunity to address complex technical issues of various crop production [2]. Fluctuation in climate conditions globally affects negatively on various Agricultural production, particularly the horticultural crops. Therefore, nano application could enhance various crop productivity under harsh environmental conditions by integrated management for various inputs to improve soil fertility, maximize crop yield improve the quality of agricultural commodities, producing safe foods, and protecting the environment from contamination by various agrochemicals like pesticides and fertilizers [3]. Agriculture crops are subjected to various biotic and abiotic stresses such as fluctuation temperatures, heat waves, rising soil salinity, drought, which increase pests and soil pathogens, and reduce crops particularly in perishable products like vegetables and fresh fruits [4]. Nanomaterials are considered the most rapidly developing edge of the field of nanotechnology, furthermore, Nano-biotechnologies offer a wide range of potential benefits to the agricultural sector [5]. There are various aspects of nano-biotechnology that has been developed in the field of agriculture, like synthetic nano-ingredient as an alternative to bulk agro-chemicals e.g. Nanofertilizers and nanocides, nano-biotechnology related with the hybrid varieties, nanoparticles that are used in packing, enhancing food processing, and increasing safety and shelf life of horticulture commodity [6]. Nano-based target delivery approach is used for different crops improvement and generates a new variety tolerant for biotic and abiotic stress conditions. Nanocides used for increasing the efficiency of crop protection, while, Nano sensors and computerized controls greatly contribute to precision farming, Nanomaterials also used to enhance soil characters and protect the environment [7]. This work discussed the role of bio-nanotechnology in improving agricultural production by using various applications that including Nano fertilizers, Nanopestecides, nan-coating materials, nano-packaging materials, and Nano biosensors. More researches are required with respect to synthesis, toxicology, mode of action, and its effective application at the farm level.

Discussion

Why we need bio-nano technology?

\section{NMS}

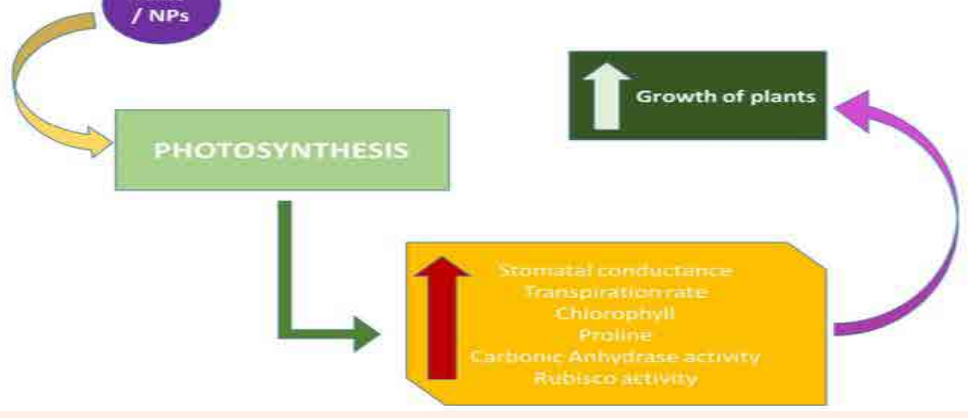

Figure 1: Increase yield, and enhance fruit quality 
Nano-bio particles are very significant in the agricultural sector due to their high stability, particularly when encapsulated with natural materials like nano chitosan. On the one hand, there is increasingly interesting to use different nano-bio materials like Nanofertilizers, Nanocides, Nano-coating materials, Nanocarrier, and Nanobiosensors in improving horticultural production [8]. From another hand, using nano-bio materials in postharvest processing improves freshness, enhances quality, and extended the shelf life of horticultural products particularly perishable products, and control disease activity during storage [9].Thus using nanotechnology in the agricultural sector provide numerous benefits to facing changing climatic conditions.

Nanotechnology could be a key tool in improving horticultural production and food security for humanity. There are different impacts of nanotechnology applications in the horticultural sector include controlled released nano fertilizer to improve crop growth, increase photosynthesis efficiency [10]. (Figure 1) increase yield, and enhance fruit quality [10].

Nano-based materials have more ability to target delivery of the determined part of the plant, which increases their effectiveness and increase plant tolerant for various environmental stress. Nanocides are used for increasing the efficiency of crop protection, while, Nanosensor and computerized controls greatly contribute to precision farming, Nanomaterials also used to enhance soil characters and protect the environment [11]. Using nano-materials in agriculture provide a different approach for different substances, for example slowing the release of fertilizers as per plant requirements, enhancing chemical delivery, and reducing environmental hazards. Nanomaterials for horticultural applications must have determined properties like effective concentration and controlled release of nutrients or pesticides in response to positive stimulation, improving targeted activity, and smart and safe delivery with minimal Eco-toxicity [6]. There are various aspects of nano-biotechnology has been developed in the field of agriculture, like synthetic nano-ingredient as alternative of bulk agro-chemicals e.g. Nanofertilizers and nanocides, nano-biotechnology related with the hybrid varieties, nanoparticles that used in packing, enhancing food processing, and increase safety and shelf life of horticulture commodity [3].

\section{What are nanoparticles?}

Nanomaterials are any materials that possess one or more dimensions that minimize than $100 \mathrm{~nm}$, including either natural or synthetic materials, also, the physical and chemical properties of nanoscale material are completely different from the bulk materials properties and play important role in different fields [12].

As per "Royal Society and Royal Academy of Engineering, 2004", synthesis of Nanoparticles are mainly by two techniques:

1. 'Top-down' systems whereas tiny manipulations of slight numbers of atoms or molecules produce the smallest possible patterns in nanoscale.

2. The "bottom-up" nano synthesis technology relies on assembling small molecules in successive steps, to synthesize nanomaterials with unique properties different from the basic components and can be identified by their special molecular structure.

In addition to the common synthesis techniques that are used for synthesis nanoparticles, there are other methods to synthesis nanoparticles by microorganisms, plants, and chemical methods,...etc. Nanomaterials have great potentials regarding their application in agricultural practice such as plant nutrition, protection, and soil improvement, there are numerous materials used to synthesize Nanoparticles include metal oxides, polymers, emulsions, silicates, lipids, and ceramics [13]. There are different approaches to synthesis Nano fertilizers like formulating a composite of nanoparticles of the nutrient itself, absorption nutrients on nanoparticles, encapsulation nutrients with a Nano-particulate polymeric shell [14].

\section{Properties of nanoparticles}

Nanoparticles have unique properties due to their small size compared to their high specific surface area. Therefore, nanomaterials have a high ability in various chemical reactions, and biological activities. Most bio-nano particles coating or encapsulated with natural materials like chitosan, so, they have more steadiness for a long time compared to other agrochemicals [15]. Bio-nanoparticles provide different ways to improve plants' resistance under various biotic and abiotic stresses, also, they increase the efficiency of various molecular interactions within the plant, which enhances plants' ability to avoid the negative effects of harsh environmental conditions [16]. Depending on their size, qualities, high surface tension, the big ratio of surface to volume, and other unique characters, as well as, the physical properties of nanoparticles that are completely different from that of the original material, and nanomaterials follow the quantum mechanics roles [17]

There are different advantages that nanomaterials gain from the unique functional properties like

1) Higher charge density and higher reactivity due to (High surface to volume ratio).

2) Nanomaterials behavior displaying as quantum mechanical, as the increase of surface area compared to volume.

3) More strength and improving heat resistance, reducing melting point, and other magnetic properties.

4) Varying in the electron transfer rate kinetics of metal nanoparticles with other adsorbed mediums.

5) Nanoparticles have reactivity that is more chemical at the edges of the forms.

6) More ability to penetrate the plant cell walls.

7) Higher mobility of nanoparticles in living cells and the environment.

\section{Classification of Nanomaterials}

There are different bases to classify the Nano fertilizers as following:

Firstly, by using techniques and applying a functional point of view it could be categorized as follow:

a) Soil application Nano fertilizers could apply directly to the soil or through irrigation systems.

b)Foliar application.

The second category of Nano fertilizers is made up of Nano-porous materials, Nano-clays, and Nano-forms of polysaccharides such as chitosan, that function as vehicles with a large surface area that increases plant absorption of using substances like Nano-particles, consequently, improves plant growth [18].

\section{Nanomaterials and Agriculture}

Due to various biotic and abiotic threats like climate change conditions, soil degradation, pests and pathogens spreading, and other factors that decrease the efficiency of applied bulk fertilizers, polluted soil, and water, as well as decrease crop productivity and reduce farmer's profits. Therefore, various nano application could be a promising solution for many challenges that facing agriculture production [19]. [20] mentioned using nanotechnology in agriculture for the first time, followed by [21] Applications of nanotechnology in agriculture are still novel techniques, practically not more than two decades only, therefore, still limiting in various sectors, from another side it is considered the vital key in improving the productivity of different crops, Nevertheless, due to increasing inadequate in global demand for food which overloading of the terrestrial ecosystems.

\section{Nano application}

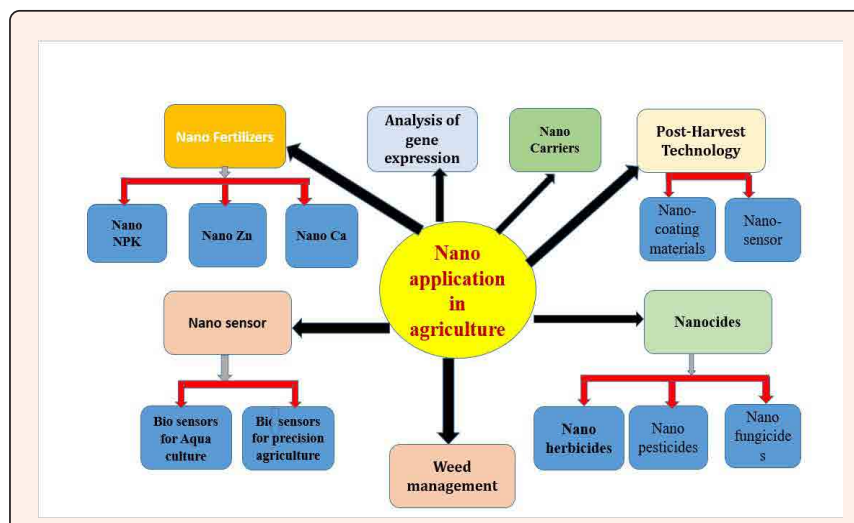

Figure 2: Schematic for nano application in agricultural sector 
Nanotechnology is used in the agricultural sector by various types (Figure 2) that include nano fertilizers (e.g. Zinc oxide nanoparticles and carbon nanotubes), nanocides, nano carriers like chitosan, nano sensors, and nano-coating materials to increase the shelf life of perishable products.

In addition, Nano-coating materials like chitosan nanoparticles, and zeolite nanoparticles are used to coat various conventional agrochemicals such as phosphorus, sulfur, while, active ingredients like validamycin, tebuconazole, and azadirachtin have been converted into nanopestecides [22]

Hereunder some application of nanotechnology in agricultural sector:

\section{Nano-fertilizers}

Currently, Nano-fertilizers represent an alternative to bulk fertilizers and reduce the accumulation of different nutrients, which may affect negatively soil characters, in addition, contamination of water may be eliminated. Nano fertilizers supply slow and steady nutrients for the plant in a determined time as per plant requirement through smart delivery systems, thereby increasing the efficiency of using fertilizers and minimizing nutrient loss and leaching in drainage water [18]. Nano fertilizers provide a good potential to deliver nutrients to specific target sites in plant cells. There are different paths to adsorb Nano fertilizers in plant tissue and adsorb rate are determined by characters of nanoparticles like size and surface properties Nanoparticles must cross the cell wall before entering the intact plant cell protoplast, therefore, the smallest nanoparticles with a diameter lesser than $(5-20 \mathrm{~nm})$ pass directly through the pores in cell wall, while, the particles with more size than $(20 \mathrm{~nm})$ could pass from the gaps in cuticle layers [23]. In addition, Soil application of Nano fertilizers increased the adsorption of nutrients from soil solution due to noticeably minor particle dimensions and larger specific surface areas. Therefore, Nano-biotechnology offers Nano-fertilizers as a new technique and alternative for conventional fertilizers, which have great potential to increase nutrient efficiency, availability for a long time, protect the environment, so, there is great attention for using Nano fertilizer in the nutrition of various horticultural crops [24].

\section{Nanocides}

Nanomaterials have more efficient and able to site-specific use due to thei distinctive physical and chemical characteristics like wide surface area. Nanomaterials offer new insights toward crop protection and play a significant role as an alternative for bulk materials of different pesticides, insecticides, and herbicides in an eco-friendly greener way [6]. Furthermore, the composition of Nanocides enhances the solubility of low soluble active ingredients, and assist in the gradual release of the active compound. In addition, Nanomaterials attain two vital aspects in pathogen and pests contro represented in their higher efficiency with tiny ecological influence and minimizing toxicity for humankind health [25]. Nanocides are highly reactive compared to the bulk pesticides, so, it used at lower doses to spray a wide area of crops, also, they could use as soil application particularly in slow-release forms such as encapsulated or coating with nano-polymers, which provide ingredients for a long time that enhancing plant protection and maintain soil health [26].

\section{Nanotechnology and packaging}

There are annually massive horticulture commodities spoiled worldwide due to various factors, particularly during post-harvest processing. Nano-biotechnology applications in food processing and packaging could improve commodity shelf life and increase fruit quality [27]. Furthermore, using nano-membrane for packaging and treatment commodity by nanomaterials extends the shelf life of the product particularly for perishable products. In addition, using coating nanomaterials improve fruit quality and increase apple fruit shelf life [28]. Currently, there are various biodegradable nanocomposites materials used in coating and backing of horticultural commodities like nanofillers, which depend on nano polymer composites such as Nanoclays, Nanonylons, and cellulose microfibrils [29]. On another side, nanomaterials such as chitosan, cellulose, and polymer are used as coating of the internal surface of packaging materials to reserve stability of the package and minimize the reaction of food products with the packaging material [30].

\section{Benefits of nano-biotechnology in backing horticulture commodity}

In addition, there are numerous nanoparticles (NPs) well known as antibacterial and antifungal impacts like $(\mathrm{AgO}, \mathrm{CuO}, \mathrm{TiO} 2, \mathrm{MgO}, \mathrm{CaO}, \mathrm{Fe} 3 \mathrm{O} 4$, and $\mathrm{ZnO}) \mathrm{NPs}$,
$[31,32]$. In addition, using Nano silver oxide increases the shelf life of apple fruits [33] Likewise, using nano-Sio2 in packaging materials improves loquat fruit quality [34]. Nowadays, numerous applications of nano-biotechnology have been used in agricultural production including:

1.Maximizing production

2.Increase the commodity shelf life

3.Enhancing food safety e.g. reducing pathogens activity.

4.Produce a new generation of packaging materials.

5.Controlling internal atmosphere.

6.Reduce the damage of different rays particularly Ultra Violet.

7zIndicate food spoilage by using Nano biosensor.

\section{Nanosensor}

There is different usage for nanosensor in horticulture production, it works in farms during cultivation to detect pathogens and determine soil humidity and the proper time for irrigation. Also, its uses during packaging processing to control gasses changes in the internal atmosphere for packages, and as indicators for food safety [35].

\section{Conclusion}

There is increasing attention to bio-nanotechnology as a key solution to different challenges that face the agricultural sector and food processing. Due to several benefits of using Nano-biotechnology such as improving plant tolerance, increasing nutrient efficiency, reducing the quantity of agrochemical consequently protect the environment, and increase plant growth and productivity. There are two main methods to manufacture (top to down), and bottom-up. While there are main methods used in the synthesis of nanoparticles, including physical, chemical, and green synthesis. Nanoparticles have numerous unique characters, which increase their ability in various chemical reactions, and biological activities. Nanoparticles are manufactured by different techniques, while, there are different unique properties of nanomaterials such as higher charge density and higher reactivity due to (High surface to volume ratio), higher penetration of plant tissues, strength, and heat resistance. There are numerous applications of nanoparticles in the agricultural sector such as nano fertilizers, nanocides, biosensors, nano-carriers, nano herbicides, applications in food processing, in addition to the application of nanotechnology in precision agriculture. Furthermore, bio-Nano application in the agricultural field sustained the environment, protecting both soil and water from pollution by agrochemicals, and increasing crop productivity.

\section{References}

1. Sivakami A, Sarankumar R, Vinodha S (2021) Introduction to Nanobiotechnology: Novel and Smart Applications. Bio-manufactured Nanomaterials p. 1-22:

2. Manjunatha SB, Biradar DP, Aladakatti YR (2016) Nanotechnology and its applications in agriculture: A review. J farm Sci 29(1): 1-13.

3. Shang Y, Hasan M, Ahammed GJ, Li M, Yin H, et al. (2019) Applications of nanotechnology in plant growth and crop protection: a review. Molecules 24(14): 2558 .

4. Abobatta WF (2021) Managing citrus orchards under climate change. MOJ Eco Environ Sci 6(2): 43-44.?

5. Archana S (2021) The Application of Nanomaterials in Agricultural Field. International Journal of Modern Agriculture 10(2): 3038-3045.)

6. Abobatta WF (2018) Nanotechnology application in agriculture. Acta Scientific Agriculture 2(6) pp.'

7. Ghormade V, Deshpande MV, Paknikar KM (2011) Perspectives for nanobiotechnology enabled protection and nutrition of plants. Biotechnology advances 29(6): 792-803?

8. Abobatta WF (2021) Precision Agriculture to Mitigate Climate Change Impacts in Horticulture. Adv Agri Tech Plant Sciences 4(1): 180054

9. Bhuyan D, Greene GW, Das RK (2019) Prospects and application of nanobiotechnology in food preservation: molecular perspectives. Critical reviews in biotechnology 39(6): 759-778.

10. Perez FAA, López ME, Guzmán C, Esquivel K (2018) A general overview 
of the benefits and possible negative effects of the nanotechnology in horticulture. Scientia Horticulturae 238: 126-137.

11. Kumar S, Nehra M, Dilbaghi N, Marrazza G, Hassan AA, et al. (2019) Nano-based smart pesticide formulations: Emerging opportunities for agriculture. Journal of Controlled Release 294: 131-153.]

12. Boverhof DR, Bramante CM, Butala JH, Clancy SF, Lafranconi M, et al. (2015) Comparative assessment of nanomaterial definitions and safety evaluation considerations. Regulatory Toxicology and Pharmacology 73(1): 137-150.

13. Lowry GV, Avellan A, Gilbertson LM (2019) Opportunities and challenges for nanotechnology in the agri-tech revolution. Nature nanotechnology 14(6): 517522 .

14. Banotra M, Kumar A, Sharma BC, Nandan B, Verma A, et al. (2017) Prospectus of use of nanotechnology in agriculture--A review. International Journal of Current Microbiology and Applied Sciences 6(12): 1541.

15. Pandey S, Klerk DC, Kim J, Kang M, Kankeu EF (2020) Eco friendly approach for synthesis, characterization and biological activities of milk protein stabilized silver nanoparticles. Polymers 12(6): 1418.

16. Bhatia R, Gulati D, Sethi G (2021) Biofilms and nanoparticles: applications in agriculture. Folia Microbiologica p. 1-12

17. Weiss J, Takhistov P, McClements D J (2006) Functional materials in food nanotechnology. Journal of food science 71(9): R107.)

18. Aziz HMA, Hasaneen MN, Omer AM (2016) Nano chitosan-NPK fertilize enhances the growth and productivity of wheat plants grown in sandy soil. Spanish Journal of Agricultural Research 14(1): 17.

19. (1999). In: Roco MC, Williams RS, Alivisatos P (Eds), Nanotechnology research directions. Vision for the Next Decade, Springer (formerly Kluwer Academic Publishers) IWGN Workshop Report 1999. Washington, US.

20. Kuzma JR, VerHage P (2006) Nanotechnology in agriculture and food production: anticipated applications. Project on Emerging Nanotechnologies, Woodrow Wilson International Center for Scholars, US.

21. Rubilar O, Diez MC, Tortella GR, Briceno G, Marcato PD, et al. (2014) New strategies and challenges for nanobiotechnology in agriculture. Journal of biobased materials and bioenergy 8(1): 1-12.

22. Konappa N, Krishnamurthy S, Arakere UC, Chowdappa S, Akbarbasha R, et al. (2021) Nanofertilizers and nanopesticides: Recent trends, future prospects in agriculture. Advances in Nano-Fertilizers and Nano-Pesticides in Agriculture pp. 281-330.

23. Su Y, Ashworth V, Kim C, Adeleye AS, Rolshausen P, et al. (2019) Delivery, uptake, fate, and transport of engineered nanoparticles in plants: a critical review and data analysis. Environmental Science: Nano 6(8): 2311-2331.]

24. Pan B, Xing B (2012) Applications and implications of manufactured nanoparticles in soils: a review. European Journal of Soil Science 63(4): 437-456.

25. Anandhi S, Saminathan VR, Yasotha P, Saravanan PT, Rajanbabu V (2020) Nano-pesticides in pest management. Journal of Entomology and Zoology Studies 8(4): 685-690.

26. Sinha K, Ghosh J, Sil PC (2017) New pesticides: a cutting-edge view of contributions from nanotechnology for the development of sustainable agricultural pest control. In New pesticides and soil sensors $\mid p p .47-79$.

27. Abobatta WF (2019) Impact of Nanotechnology in the Agro-Food sector. Arch Nano Op Acc J 2(1): pp.

28. Li X, Li W, Jiang Y, Ding Y, Yun J, et al. (2011) Effect of nano-ZnO-coated active packaging on quality of fresh-cut 'fuji' apple. Int J Food Sci. Technol 46: 19471955

29. Purohit R, Mittal A, Dalela S, Warudkar V, Purohit K, et al. (2017) Social, environmental and ethical impacts of nanotechnology. Mater. Today Proc 4(4): 5461-5467.

30. Yildirim S, Röcker B (2018) Active packaging. In Nanomaterials for Food Packaging. Elsevier pp. 173-202.

31. Ahari H, Anvar AA, Ataee M, Naeimabadi M (2021) Employing Nanosilver, Nanocopper, and Nanoclays in Food Packaging Production: A Systematic Review. Coatings 11(5): 509.

32. Cheeseman S, Christofferson AJ, Kariuki R, Cozzolino D, Daeneke T, et al (2020) Antimicrobial Metal Nanomaterials: From Passive to Stimuli-Activated Applications. Adv Sci 7(10): 1902913

33. Zhou L, Lv S, He G, He Q, Shi BI (2011) Effect of pe/ag2o nano-packaging on the quality of apple slices. Journal of Food Quality 34(3): 171-176:

34. Wang L, Shao S, Madebo MP, Hou Y, Zheng Y, et al. (2020) Effect of nano-SiO2 packing on postharvest quality and antioxidant capacity of loquat fruit under ambient temperature storage. Food chemistry 315: 126295 .

35. Shang Y, Hasan,M, Ahammed GJ, Li M, Yin H, et al. (2019) Applications of nanotechnology in plant growth and crop protection: a review. Molecules 24(14): 2558 